\title{
The Nexus between Child Marriage and Women Empowerment with Physical Violence in Two Culturally Distinct States of India
}

\author{
Jayakant Singh ${ }^{1}$ and Enu Anand ${ }^{2}$ \\ ${ }^{1}$ School of Health Systems Studies, Tata Institute of Social Sciences, Mumbai 400088, India \\ ${ }^{2}$ International Institute for Population Sciences, Mumbai 400088, India \\ Correspondence should be addressed to Jayakant Singh; singhjayakant.tiss@gmail.com
}

Received 16 July 2015; Revised 25 October 2015; Accepted 26 October 2015

Academic Editor: Sally Guttmacher

Copyright (c) 2015 J. Singh and E. Anand. This is an open access article distributed under the Creative Commons Attribution License, which permits unrestricted use, distribution, and reproduction in any medium, provided the original work is properly cited.

\begin{abstract}
Summary. We investigated the relationship between child marriage among young women and their level of empowerment with spousal physical violence in two culturally distinct states of India (Bihar and Tamil Nadu) using nationally representative survey data. Empowerment index was calculated taking into account parameters such as mobility, economic independence, and decisionmaking power of a woman using Principal Component Analysis method. Lower level of women empowerment was significantly associated with physical violence in Tamil Nadu $(\mathrm{OR}=2.38, p<0.01)$ whereas marriage before the age of 15 was associated with physical violence in Bihar $(\mathrm{OR}=3.27, p<0.001)$. The mean age at marriage was low among women who reported physical violence as compared to those who did not report physical violence across Bihar and Tamil Nadu and at all India level. Although the majority of the women in Tamil Nadu justified wife beating and witnessed father beating mother as compared to the women from Bihar, however, they were less likely to report physical violence than women from Bihar. Factors contributing to physical violence are distinct in Bihar and Tamil Nadu. Culture specific intervention may be considered while planning intervention strategies to curb spousal violence against women.
\end{abstract}

\section{Introduction}

UNICEF defines child marriage as any marriage that occurs before the age of 18 for girls. A recent study by UNICEF [1] reveals alarming facts about child marriage worldwide: an estimated number of more than 720 million girls currently living were married before the age of 18; one in three child marriages occurred before the age of 15; South Asia alone is home to nearly half of all the child marriages in the world (42\%); and most shockingly, every third child marriage in the world takes place in India. National Population Policy 2000 [2], National Youth Policy 2003 [3], and the Prohibition of Child Marriage Act 2006 [4] are few of the most recent policies and laws formed in India to prevent child marriage but have not been very effective so far in reduction of child marriage.

Evidence suggests that early marriage limits knowledge, skills, resources, mobility, autonomy, and social support of young girls and those who lack this are extremely vulnerable to physical and sexual violence and psychological and economic abuse [5, 6]. Early marriage leads to curtailment of school education [5]. The chance of receiving quality education is a distant reality for the child bride and higher levels of dropout from the school are a very common phenomenon [5]. Girls who are married at an early age are also likely to report an early pregnancy with considerable exposure to the risk of violence [6]. Negative consequences of child marriage on the physical health and mental wellbeing of the child bride are vividly demonstrated [5, 7-10]. The vulnerability of child bride in relation to physical abuse in different cultural contexts has however not received adequate attention. Little work that has focused on India [11-16] however suggested that there is an increased risk of Intimate Partner Violence among child brides. A few studies have acknowledged lack of autonomy in women to be a risk factor associated with higher levels of violence within marriage $[5,17,18]$. While the situation of child bride is somewhat documented in India, evidence on the ways in which child bride may be a risk factor 
for physical violence in culture specific context is limited [19]. In India, being a large country with diverse culture and tradition, the causes of physical violence may vary from state to state.

How child marriage and women empowerment are related to the risk of physical violence is the main objective of this paper. The pattern and prevalence of physical violence in relation to women empowerment and child marriage from two culturally distinct states with high prevalence of physical violence are the broader scope of the study. Bihar and Tamil Nadu are the two states selected in this study for the following reasons: these two states are socioculturally distinct, located in the two different spectrums of India. Bihar is in the northern part of India whereas Tamil Nadu is in the southern part of India. Kinship system in India is not homogeneous across states. It also varies across different castes and strata within a geographical region. Although such variation is persistent, there is a clear north and south divide in the Indian kinship structure. Dyson and Moore (1983) have pointed out three key differences between the north Indian and south Indian system [20]: in north India, the spouses are unrelated and they are not from the same village indicating marriage rules to be exogamic in nature. Secondly, males cooperate with other adult males within blood relation for any kind of help. And finally, women do not inherit property from their parents. Socially, the wife givers are inferiors to the wife takers and often the women do not have a choice in the process of mate selection in north India. In contrast, often the preferred form of marriage is cross-cousin marriage in south India. Males in south India are also likely to engage in relation and mutual support with that of the wife's family as much as with their own blood relation. Women in south India can inherit property from their parents. In south Indian context, women are more likely to be married to a known person in contrast to their north Indian counterpart. Conversely, the behaviour of women in the north Indian society is more likely to be rigidly observed whereas in south India, the woman may have already known the in-law's family members. Interestingly, there is greater freedom in the case of the women in south India in terms of keeping relation with their natal home as opposed to the north Indian women. In fact, the majority of the newly married couples are encouraged to live in an independent nuclear family in south India unlike in north India. Karve (1953) expressed that the women in the south enjoyed greater freedom and a higher social status as compared to women in north India [21].

Women autonomy and mobility indicators observed in NFHS-3 (National Family Health Survey) [11] portrayed somewhat better condition of women in Tamil Nadu than in Bihar. The powerlessness among females is understood to be more acute in north India as compared to south India [14]. In addition, Tamil Nadu also performed better than Bihar in some of the health and development indicators. For example, female literacy rate was 73.86 in Tamil Nadu versus 53.33 in Bihar; sex ratio was 995 in Tamil Nadu versus 916 in Bihar; total fertility rate was 1.7 in Tamil Nadu versus 3.6 in Bihar; infant mortality rate in Bihar was twice that of Tamil Nadu; and maternal mortality rate in Bihar was more than the double compared to Tamil Nadu [22-24]. Although the sociocultural contexts of these two states are different, prevalence of physical violence is the highest in these states. As per NFHS-3, physical violence among the young married women aged 20-24 was the highest in Bihar (45.7\%) from among the northern Indian states and it was the highest in Tamil Nadu (26.1\%) from among the southern Indian states. Such discrepancies are curious as these states are not only culturally different but are in different stages of socioeconomic and demographic fronts. We therefore examined whether factors such as child marriage and women empowerment are related to physical violence.

\section{Materials and Methods}

2.1. Ethical Statement. The National Family Health Survey (NFHS) was conducted under the supervision of the International Institute for Population Sciences (IIPS), Mumbai, India. The ORC Macro institutional review board approved the data collection procedures. Formal consent was obtained from the respondents before conducting interview. The study is based on anonymous public use datasets without any identification information of the survey participants. Survey data is available upon request.

2.2. Data. We used data from a nationally representative cross-sectional survey in India. The National Family Health Survey (NFHS-3) conducted in 2005-06 is a similar version to Demographic Health Survey conducted in other low and middle income countries. In this survey, all women in the age group 15-49 were eligible as survey participants. The domestic violence module was however administered only to one eligible woman per household when her privacy was ensured. Sampling frame was drawn from the 2001 Census of India. A list of villages for the rural area and a list of wards from urban area were considered as sampling frame. Further, the sample was stratified by various demographic characteristics. The interviews were carried out by female investigators to encourage openness on sensitive topics such as violence. More details about the survey design can be found elsewhere [11]. The total sample size for India, Bihar, and Tamil Nadu was 10514, 373, and 523, respectively, after restricting the analysis to currently married women aged 2024 in order to record the experiences of recently married women.

2.3. Measures. The key outcome variable was experience of physical violence in the last 12 months preceding the survey. All currently married women administered with the domestic violence module were asked a series of questions on experience of physical and sexual violence and emotional violence. A woman was considered to have experienced physical spousal violence if she responded yes to any of the seven questions: that her husband ever slapped her; twisted her arm or pulled her hair; pushed or shook her or threw something at her; punched her with his fist or with something that could hurt her; kicked her, dragged her, or beat her up; tried to choke her or burn her on purpose; threatened or attacked her with a knife, gun, or any other weapon. These 
TABLE 1: Frequency distribution of key variables (unweighted).

\begin{tabular}{|c|c|c|c|}
\hline Characteristics & India & Bihar & Tamil Nadu \\
\hline \multicolumn{4}{|l|}{ Age at marriage } \\
\hline Married before the age of 15 & 26.9 & 39.1 & 14.9 \\
\hline Married in the age from 15 to 17 & 27.4 & 29.5 & 23.7 \\
\hline Married after the age of 18 & 45.6 & 31.4 & 61.4 \\
\hline \multicolumn{4}{|l|}{ Level of women empowerment } \\
\hline Low & $*$ & 43.6 & 19.0 \\
\hline Medium & $*$ & 31.7 & 40.4 \\
\hline High & * & 24.9 & 40.6 \\
\hline$\%$ of women who experienced physical violence in the last 12 months & 21.7 & 46.6 & 30.6 \\
\hline Total $(N)$ & 10514 & 373 & 523 \\
\hline
\end{tabular}

${ }^{*}$ Women empowerment index was calculated using PCA; all the scores were divided into three equal parts; therefore, the cell is left blank.

sets of questions were based on revised Conflict Tactics Scale [25].

2.4. Covariates. The predictor variables considered in the study included age at marriage (child marriage and adult marriage). Marriage before the age of 18 was considered as child marriage as 18 is the legal age for marriage for girls in India. Further child marriage is bifurcated into marriage before the age of 15 and marriage between 15 and 17 years of age, in order to understand experiences of those child brides who were very young at the time of their marriage. Women empowerment index was computed using a set of questions that measured women's mobility, financial independence, and decision-making power in the household: whether a woman ever worked in the last 12 months and earned in cash, whether she had any bank account or savings, whether she had final say on own health care, final say on making large household purchases, final say on making household purchases for daily needs, final say on visits to family or relatives, and final say on deciding what to do with money husband earns, and whether a woman was allowed to go to market alone, allowed to go to the health facility alone, and allowed to go to places outside the village/community alone. Empowerment index was computed using Principal Component Analysis. Cronbach's alpha was calculated through reliability analysis to check the internal consistency of the variables selected for empowerment index [26]. The alpha coefficient for the 10 variables for empowerment score was 0.755 suggesting the elements having a good internal consistency.

Age at marriage and women empowerment index were employed as two key predictor variables. Other covariates described as risk factors [12, 16, 27-29] were also used to control in regression analysis. These included age difference between husband and wife, ever witnessing violence between mother and father, husband's alcohol use, household structure, justifying wife beating if she goes out without telling husband, neglecting the house or children, arguing with husband, refusing to have sex with husband, not cooking food properly, husband suspecting her of being unfaithful; or her showing disrespect for the in-laws. Socioeconomic variables such as educational level of the woman, husband's level of education, occupation of the woman, occupation of the husband, wealth index, place of residence, religion of the woman, and caste of the women are shown in bivariate analysis and controlled in the regression model.

2.5. Data Analysis. Univariate, bivariate, and multivariate techniques are used in the study to analyze data. Effect of age at marriage and women empowerment was tested in the logistic regression model with other covariates mentioned above. Separate domestic violence weights were used to adjust for sampling variation in the analysis. National domestic violence weight was employed when analysis was carried out at the national level and state domestic violence weight was employed whenever analysis was carried out at the state level. The analysis was restricted to currently married women in the age group of 20-24 to examine more recent child marriage practice and its association with physical violence. Data analysis was performed using IBM SPSS 22.

\section{Results}

Table 1 presents the unweighted frequency distribution of key variables considered in the study. The prevalence of physical violence and the distribution of age at marriage and level of women empowerment in India, Bihar, and Tamil Nadu are shown in this table. Prevalence of physical violence as well as child marriage was higher in Bihar as compared to Tamil Nadu. Higher levels of women empowerment were observed in Tamil Nadu as compared to Bihar.

Profile of the respondents (Table 2) reflected a few similar and distinct conditions of women in two different parts of India. The respondents from Tamil Nadu were better educated and were more likely to work for wages than the women from Bihar. The characteristics of their partner also demonstrated somewhat similar picture. The majority of the women in both states were married for more than 5 years at the time of survey. Nuclear family households were more common in Tamil Nadu whereas joint family was the dominant form of household in Bihar. The majority of the respondents in Tamil Nadu were from urban area (53\%) and belonged to middle wealth index group (64\%). On the contrary, the majority of the respondents from Bihar were from low wealth index group (54\%) and were from rural area 
TABLE 2: Profile of the respondents in the age group 20-24 and their partner, NFHS-3 2006-07, India.

\begin{tabular}{|c|c|c|c|}
\hline Background characteristics & India & Bihar & Tamil Nadu \\
\hline \multicolumn{4}{|c|}{ Witnessed father beating mother } \\
\hline No & 75.5 & 66.1 & 57.6 \\
\hline Yes & 18.6 & 24.5 & 39.4 \\
\hline Do not know & 5.8 & 9.4 & 3.1 \\
\hline \multicolumn{4}{|l|}{ Wife beating justified } \\
\hline Not justified & 44.9 & 46.2 & 32.8 \\
\hline Justified any one reason & 55.1 & 53.8 & 67.2 \\
\hline \multicolumn{4}{|l|}{ Husband consuming alcohol } \\
\hline No & 66.6 & 60.1 & 62 \\
\hline Yes & 33.4 & 39.9 & 38 \\
\hline \multicolumn{4}{|c|}{ Educational level of respondent } \\
\hline No education & 33.8 & 58.7 & 13.6 \\
\hline Primary & 15.8 & 12.6 & 18.5 \\
\hline Secondary & 45.1 & 26.8 & 56 \\
\hline Higher & 5.4 & 1.9 & 11.9 \\
\hline \multicolumn{4}{|l|}{ Husband's education } \\
\hline No education & 20.1 & 34.6 & 12 \\
\hline Primary & 15.0 & 11.8 & 18.4 \\
\hline Secondary & 53.5 & 42.4 & 57.7 \\
\hline Higher & 10.8 & 10.2 & 11.9 \\
\hline Do not know & 0.7 & 1.1 & - \\
\hline \multicolumn{4}{|l|}{ Occupation of the respondent } \\
\hline Not working & 69.4 & 79.6 & 68.6 \\
\hline Agricultural & 18.7 & 15.5 & 13.2 \\
\hline Nonagricultural & 4.6 & 2.4 & 6.7 \\
\hline Manual labor & 7.3 & 2.4 & 11.5 \\
\hline \multicolumn{4}{|l|}{ Husband's occupation } \\
\hline Not working & 1.1 & 2.7 & 0.2 \\
\hline Agricultural & 24.6 & 21.7 & 17.6 \\
\hline Nonagricultural & 30.6 & 31.9 & 23.5 \\
\hline Manual labor & 43.6 & 43.7 & 58.7 \\
\hline \multicolumn{4}{|l|}{ Spousal age difference } \\
\hline Less than 5 years & 41.9 & 40.2 & 35 \\
\hline 5 to 9 years & 41.7 & 44.5 & 45.5 \\
\hline 10 and above & 16.4 & 15.3 & 19.5 \\
\hline \multicolumn{4}{|l|}{ Place of residence } \\
\hline Urban & 39.4 & 35.1 & 53.5 \\
\hline Rural & 60.6 & 64.9 & 46.5 \\
\hline \multicolumn{4}{|l|}{ Household structure } \\
\hline Nuclear & 46.4 & 43.3 & 61.6 \\
\hline Nonnuclear & 53.6 & 56.7 & 38.4 \\
\hline \multicolumn{4}{|l|}{ Household wealth } \\
\hline Poor (40) & 34.4 & 54.4 & 19.5 \\
\hline Middle (20) & 46.6 & 33.2 & 64.2 \\
\hline Rich (40) & 19.0 & 12.3 & 16.3 \\
\hline \multicolumn{4}{|l|}{ Caste/tribe } \\
\hline $\mathrm{SC} / \mathrm{ST}$ & 33.2 & 15.0 & 31.2 \\
\hline Others & 66.8 & 85.0 & 68.8 \\
\hline \multicolumn{4}{|l|}{ Religion } \\
\hline Hindu & 74.8 & 80.4 & 88.9 \\
\hline Muslim & 14.4 & 19.3 & 5 \\
\hline Others & 10.9 & 0.3 & 6.1 \\
\hline Total $(N)$ & 10514 & 373 & 523 \\
\hline
\end{tabular}

(65\%). A somewhat different picture emerged with regard to responses pertaining to whether respondent witnessed father beating mother and on responses related to justification provided for wife beating in both states. The majority of the respondents in Tamil Nadu considered wife beating a justifiable form of behaviour (67\%) as compared to the respondents from Bihar (54\%). Similarly, higher percentage of the respondents in Tamil Nadu witnessed their father beating mother (39\%) as compared to the respondents from Bihar (25\%).

The results from the bivariate analysis (Table 3) highlighted the notion that physical violence was significantly higher among child brides. This is persistent in Tamil Nadu where more than half of the child brides who got married before the age of 15 experienced physical violence during the last one year preceding the survey. One in three who got married within the age of 15-17 experienced physical violence in Tamil Nadu. Although the corresponding figure for Bihar is much higher, the difference is not statistically significant. Physical violence decreased significantly as the age at marriage increased in Tamil Nadu and at all India level. Bivariate results of women empowerment index and physical violence did not show any statistical significance for both states; however, the result was significant at all India level. The experience of physical violence did not change much with the level of women empowerment index. Physical violence ranged from 22 percent to 25 percent among women in high empowerment index and middle empowerment index groups at India level.

The respondents who witnessed their father beating mother, who justified the behavior of their partner on beating them, and whose husband consumed alcohol were particularly vulnerable to physical violence. A significant and consistent relationship with physical violence across India and the selected two states was observed with these three characteristics. More than 60 percent of women in Bihar and about 30 to 40 percent in Tamil Nadu experienced physical violence in the last one year preceding the survey with these three characteristics. Further, higher education of the respondent and her husband as well as better occupation status of the respondent was likely to be protective of physical violence across states and at all India level.

In a similar fashion, some of the sociodemographic factors also showed significant differences. Physical violence by household structure revealed that joint family was protective of physical violence. The result was significant at the national level and in Tamil Nadu. Physical violence among the respondents was double among poor household as compared to rich household in Bihar. Bihar and Tamil Nadu, conceptualized as culturally distinct states, illustrated that physical violence was higher among lower caste particularly among the Scheduled Caste as compared to the upper caste. Two out of three women from Scheduled Caste household in Bihar and one in three in Tamil Nadu were likely to experience physical violence.

3.1. Mean Differences in Age at Marriage by Experience of Physical Violence. Table 4 shows mean difference in age at marriage among those who experienced physical violence and those who did not. Mean age at marriage varied considerably in Bihar and Tamil Nadu and at all India level. Although 
TABLE 3: Percentage of women in the age group 20-24 who experienced physical violence in the last 12 months, NFHS-3 2006-07, India.

\begin{tabular}{|c|c|c|c|c|c|c|}
\hline \multirow{2}{*}{$\begin{array}{l}\text { Background characteristics } \\
\text { Age at marriage }\end{array}$} & \multicolumn{2}{|c|}{ India } & \multicolumn{2}{|c|}{ Bihar } & \multicolumn{2}{|c|}{ Tamil Nadu } \\
\hline & $* * *$ & & & & $* * *$ & \\
\hline Before the age of 15 & 30.4 & 2830 & 44.1 & 146 & 52.4 & 78 \\
\hline Between 15 and 17 & 26.8 & 2885 & 52.2 & 110 & 32.0 & 124 \\
\hline After the age of 18 & 16.7 & 4799 & 41.0 & 117 & 18.3 & 321 \\
\hline Women empowerment index & $* * *$ & & & & & \\
\hline Low & 23.3 & 3496 & 40.9 & 161 & 24.5 & 99 \\
\hline Middle & 25.2 & 3489 & 55.9 & 116 & 26.9 & 211 \\
\hline High & 21.9 & 3486 & 41.6 & 92 & 26.1 & 212 \\
\hline Witnessed father beating mother & $* * *$ & & $* * *$ & & $* * *$ & \\
\hline No & 18.7 & 7931 & 40.5 & 246 & 17.8 & 301 \\
\hline Yes & 41.6 & 1958 & 67.2 & 91 & 40.9 & 206 \\
\hline Do not know & 26.9 & 611 & 36.4 & 35 & 15.0 & 16 \\
\hline Wife beating justified & $* * *$ & & $* * *$ & & $* *$ & \\
\hline Not justified & 18.7 & 4492 & 31.3 & 166 & 18.7 & 163 \\
\hline Justified any one reason & 27.5 & 5507 & 58.1 & 193 & 31.3 & 334 \\
\hline Husband consuming alcohol & $* * *$ & & $* * *$ & & $* * *$ & \\
\hline No & 18.2 & 6993 & 34.3 & 224 & 18.6 & 324 \\
\hline Yes & 37.6 & 3511 & 65.4 & 149 & 41.1 & 199 \\
\hline Educational level of respondent & $* * *$ & & $* *$ & & $* * *$ & \\
\hline No education & 31.1 & 3552 & 53.2 & 219 & 27.5 & 71 \\
\hline Primary & 27.6 & 1658 & 37.3 & 47 & 41.3 & 97 \\
\hline Secondary & 17.3 & 4739 & 32.4 & 100 & 25.2 & 293 \\
\hline Higher & 5.5 & 565 & 31.7 & 7 & 10.4 & 62 \\
\hline Husband's education & $* * *$ & & $* * *$ & & $*$ & \\
\hline No education & 34.8 & 2105 & 60.9 & 129 & 35.6 & 63 \\
\hline Primary & 31.0 & 1572 & 50.5 & 44 & 32.3 & 96 \\
\hline Secondary & 19.6 & 5613 & 40.1 & 158 & 25.1 & 302 \\
\hline Higher & 10.4 & 1132 & 13.3 & 38 & 12.9 & 62 \\
\hline Do not know & 23.0 & 71 & 4.5 & 4 & 0.0 & 0 \\
\hline Occupation of the respondent & $* * *$ & & $* *$ & & $* * *$ & \\
\hline Not working & 21.0 & 7293 & 42.0 & 297 & 20.5 & 359 \\
\hline Agricultural & 30.1 & 1967 & 58.5 & 58 & 33.9 & 69 \\
\hline Nonagricultural & 19.8 & 482 & 11.9 & 9 & 22.0 & 35 \\
\hline Manual labour & 30.2 & 767 & 88.4 & 9 & 48.7 & 60 \\
\hline Husband's occupation & $* * *$ & & $*$ & & & \\
\hline Not working & 14.5 & 118 & 16.3 & 10 & 0.0 & 1 \\
\hline Agricultural & 26.1 & 2583 & 50.1 & 81 & 30.9 & 92 \\
\hline Nonagricultural & 17.0 & 3212 & 37.3 & 119 & 19.0 & 123 \\
\hline Manual labour & 26.6 & 4567 & 49.8 & 163 & 27.2 & 307 \\
\hline Spousal age difference & $* * *$ & & & & & \\
\hline Less than 5 years & 24.1 & 4393 & 48.2 & 150 & 31.7 & 183 \\
\hline 5 to 9 years & 22.6 & 4369 & 44.7 & 166 & 22.0 & 238 \\
\hline 10 and above & 25.2 & 1722 & 39.8 & 57 & 26.2 & 102 \\
\hline Place of residence & $* * *$ & & & & & \\
\hline Urban & 20.3 & 4141 & 45.1 & 131 & 27.8 & 280 \\
\hline Rural & 24.8 & 6373 & 45.8 & 242 & 24.5 & 243 \\
\hline Household structure & $* * *$ & & & & $* *$ & \\
\hline Nuclear & 29.8 & 4551 & 48.8 & 138 & 32.0 & 309 \\
\hline Nonnuclear & 20.2 & 5257 & 43.8 & 181 & 20.6 & 193 \\
\hline
\end{tabular}


TABLe 3: Continued.

\begin{tabular}{|c|c|c|c|c|c|c|}
\hline \multirow{2}{*}{$\begin{array}{l}\text { Background characteristics } \\
\text { Household wealth }\end{array}$} & \multicolumn{2}{|c|}{ India } & \multicolumn{2}{|c|}{ Bihar } & \multicolumn{2}{|c|}{ Tamil Nadu } \\
\hline & $* * *$ & & $* *$ & & & \\
\hline Poor (40) & 30.7 & 3612 & 51.4 & 203 & 38.6 & 102 \\
\hline Middle (20) & 21.7 & 4904 & 41.4 & 124 & 26.9 & 336 \\
\hline Rich (40) & 10.6 & 1998 & 25.4 & 46 & 4.2 & 85 \\
\hline Religion & $* * *$ & & & & & \\
\hline Hindu & 23.1 & 7859 & 45.8 & 300 & 26.8 & 465 \\
\hline Muslim & 26.7 & 1508 & 45.3 & 72 & 20.5 & 26 \\
\hline Others & 22.6 & 1147 & - & 1 & 19.9 & 32 \\
\hline Caste/tribe & $* * *$ & & $* * *$ & & $* *$ & \\
\hline SC/ST & 27.7 & 3493 & 67.4 & 56 & 33.7 & 163 \\
\hline Others & 22.0 & 7021 & 41.7 & 317 & 22.8 & 360 \\
\hline Total & 23.6 & 10514 & 45.7 & 373 & 26.1 & 523 \\
\hline
\end{tabular}

$\%$ is based on weighted sample and $N$ is unweighted sample, Chi-Square value: ${ }^{*} p<0.05$; $^{* *} p<0.01 ;{ }^{* * *} p<0.001$.

TABLE 4: Mean differences in age at marriage by experience of physical violence in the last 12 months, NFHS-3 2006-07, India.

\begin{tabular}{|c|c|c|c|c|c|c|c|c|c|}
\hline \multirow{2}{*}{$\begin{array}{l}\text { Experience of physical violence } \\
\text { in the last } 12 \text { months }\end{array}$} & \multicolumn{3}{|c|}{ India } & \multicolumn{3}{|c|}{ Bihar } & \multicolumn{3}{|c|}{ Tamil Nadu } \\
\hline & Mean & $N$ & SD & Mean & $N$ & SD & Mean & $N$ & SD \\
\hline No & 17.41 & 8232 & 2.646 & 16.7 & 199 & 2.439 & 18.44 & 363 & 2.517 \\
\hline Yes & 16.38 & 2282 & 2.374 & 16.08 & 174 & 1.995 & 17.64 & 160 & 2.556 \\
\hline Total & 17.19 & 10514 & 2.624 & 16.41 & 373 & 2.261 & 18.2 & 523 & 2.553 \\
\hline
\end{tabular}

mean age at marriage in Tamil Nadu was in confirmation to the norm of legal age at marriage in India, that is, age 18 , the difference in age at marriage between women who experienced physical violence and those who did not was about 10 months (0.8 years). This difference is somewhat lower in Bihar (7 months or 0.62 years) between those who experienced physical violence and those who did not. However, the overall mean age at marriage in Bihar was abysmally low at 16.4 years which is much below the national average of 17.2 years. The difference in mean age at marriage between those who experienced physical violence and those who did not at the national level was slightly more than one year (1.03 years).

3.2. Determinants of Physical Violence Experienced by Young Women. Results from logistic regression (Table 5) showed women empowerment and age at marriage as significant predictors of physical violence. After controlling for socioeconomic and demographic factors associated with physical violence, the results at India level predicted that women from low empowerment index were 1.36 times more likely at risk to experience physical violence $(\mathrm{OR}=1.36, p<0.001)$, and the women in medium empowerment index were 1.21 times more likely to experience physical violence as compared to women in high empowerment index $(\mathrm{OR}=1.20, p<0.001)$. The respondents who got married before the age of 15 were 1.38 times more likely and those who got married between the ages of 15-17 were 1.34 times more likely to experience physical violence $(\mathrm{OR}=1.38, p<0.001$; OR $=1.34, p<$ $0.001)$, respectively, as compared to those who got married after the age of 18 at all India level. The respondents who were in the medium empowerment index were 2.38 times more likely to experience physical violence as compared to women in high women empowerment index in Tamil Nadu (OR = 2.38, $p<0.01)$. Age at marriage was significantly associated in case of Bihar. The finding from the logistic regression predicted that respondents who got married before the age of 15 were 3.27 times more likely to experience physical violence as compared to those who got married after the age of 18 (OR $=3.27, p<0.001)$ in Bihar.

\section{Discussion}

The findings from the study underscored risk of physical violence to be associated with child marriage and relatively low level of women empowerment. The results from the logistic regression analysis suggested that lower levels of women empowerment were associated with physical violence in Tamil Nadu and child marriage in Bihar. Low level of education, economic status, and rural centric disadvantage were observed in Bihar compared to Tamil Nadu curtailing women from Bihar from losing their bargaining power in the marital relation. The state of powerlessness of women, particularly among the child brides in North India, was acknowledged in various other studies $[14,16]$ leading to vulnerable condition for violence against women in Bihar. On the other hand, the culture of marrying a known person from a relation may have been protective of violence in case of Tamil Nadu. It may be further observed that bivariate analysis indicated joint family to be protective of physical violence in Tamil Nadu but not so in case of Bihar. Joint family and cross-cousin marriage may work as combined 
TABLE 5: Logistic regression model for experience of physical violence by women (20-24) during the last 12 months in India, Bihar, and Tamil Nadu, NFHS-3 2006-07.

\begin{tabular}{|c|c|c|c|c|c|c|}
\hline & \multicolumn{2}{|c|}{ India } & \multicolumn{2}{|c|}{ Bihar } & \multicolumn{2}{|c|}{ Tamil Nadu } \\
\hline & OR & CI at $90 \%$ & OR & CI at $90 \%$ & OR & CI at $90 \%$ \\
\hline \multicolumn{7}{|l|}{ Women empowerment } \\
\hline Low & $1.360^{* * *}$ & $1.180-1.567$ & 1.411 & $(0.766-2.598)$ & 0.851 & $(0.436-1.662)$ \\
\hline Medium & $1.216^{* * *}$ & $1.062-1.392$ & 1.388 & $(0.848-2.27)$ & $2.387^{* *}$ & $(1.194-4.77)$ \\
\hline \multicolumn{7}{|l|}{ High (reference) } \\
\hline \multicolumn{7}{|l|}{ Age at marriage } \\
\hline Before 15 & $1.384^{* * *}$ & $1.198-1.599$ & $3.279^{* * *}$ & $(1.786-6.019)$ & 1.134 & $(0.571-2.251)$ \\
\hline $15-17$ & $1.349^{* * *}$ & $1.175-1.549$ & 1.101 & $(0.649-1.869)$ & 1.078 & $(0.55-2.111)$ \\
\hline After 18 (reference) & \multicolumn{2}{|c|}{$R^{2}=0.182$} & \multicolumn{2}{|c|}{$R^{2}=0.362$} & \multicolumn{2}{|c|}{$R^{2}=0.316$} \\
\hline
\end{tabular}

Significant at 90 percent; ${ }^{* * *} p<0.001,{ }^{* *} p<0.01$.

Model is controlled for all the background characteristics considered in the bivariate table.

deterrent factor for physical violence in the culturally distinct state of Tamil Nadu unlike Bihar. Although the majority of the women in Tamil Nadu compared with Bihar were better off in terms of education, work status, wealth index, and so forth, lower levels of women empowerment were a significant predictor of violence against women in Tamil Nadu and not so in case of Bihar.

The role of intergenerational violence or the respondent witnessing father beating mother had a distinct effect in these two culturally different states. Comparatively, the majority of the women in Tamil Nadu compared with Bihar witnessed their father beating mother but intergenerational violence showed little effect on experience of physical violence amongst the women from Tamil Nadu. On the other hand, the majority of women from Bihar who witnessed their father beating mother reported physical violence. The women who justified wife beating if she went out without telling husband, neglected the house or children, argued with husband, refused to have sex with husband, did not cook food properly, was suspected by her husband of being unfaithful; or showed disrespect for the in-laws were considered to have alleviated risk of experiencing physical violence [16, 27-29]; however, a comparatively less percentage of women who justified wife beating in Tamil Nadu than Bihar reported physical violence.

One of the reasons for the relatively low level of violence among those women who justify wife beating behavior in Tamil Nadu may be due to underreporting of violence or accepting violence as part of one's life. It may be understood that the women who justified wife beating were those with low level of women empowerment. More studies are required to understand the relationship between justifying wife beating as well as witnessing father beating mother and physical violence in different cultural context. The culturally different states are likely to demonstrate different risk factors as evident in this study.

Mean age at marriage between the respondents who experienced violence during the last one year and those who did not had a considerable gap. The differences in mean age at marriage were higher in Tamil Nadu as compared to Bihar. The mean age at marriage was low among those who reported physical violence as compared to those who did not report physical violence. Child marriage is highly prevalent in Bihar and therefore age at marriage by experiences of physical violence did not vary much unlike in case of Tamil Nadu. It was observed that physical violence was higher among Scheduled Caste and poor women across Bihar and Tamil Nadu. It may be indicative that regardless of distinct culture, women from poor socioeconomic strata are vulnerable to physical violence.

The current study adds on to prior research conducted on factors associated with physical violence. The findings confirm the existing literature that investigated the role of child marriage in physical violence $[5,7-10]$ and demonstrated that child marriage increases the risk of physical violence specifically in different sociocultural settings as in the case of Bihar. On the contrary, this study also confirms previous studies that have found a negative association between the level of women empowerment and physical violence [5, 17, 18]. Yet, this cannot be generalized as different cultural contexts although it restricts women's movement and autonomy but protects them from physical violence. Many of the earlier studies did not examine the role of age at marriage as well as women empowerment together with physical violence of a recent age cohort of women. The need to study physical violence against women in a distinct cultural setting such as Tamil Nadu, irrespective of its socioeconomic development [19], is addressed in this paper. The study highlights that women from culturally different states can respond in a different fashion to physical violence. In order to better understand the relation between whether, how, and why in culturally distinct contexts age at marriage and women empowerment with physical violence are related, future qualitative investigation is needed.

While results from the current study provide important insights into child marriage and relatively low level of women empowerment to be associated with physical violence, the results must be interpreted in light of a few limitations. The outcome of physical violence is based on self-report. Underreporting of incidence is possible due to social desirability and recall biases. The study does not suggest any directional linkages between child marriage and physical violence or 
women empowerment and physical violence because of the fact that the analysis is carried out from cross-sectional data. Thus, one cannot be certain as to whether early marriage causes physical violence or whether lower levels of women empowerment cause physical violence or whether any other factor perpetrates violence. Child marriage may be a precursor to the experience of physical violence as in the case of India where premarital sex is largely absent and therefore physical violence may have taken place after marriage [16]. Small sample size particularly in the case of Bihar has affected the estimates although appropriate sampling weights were used. Finally, this study is specific to women in the age group of 20-24 and therefore cannot be generalized for all women.

\section{Conclusion}

The study examined the relationship between age at marriage and level of women empowerment with the risk of experiencing physical violence in two culturally distinct states, namely, Bihar and Tamil Nadu. Child marriage and women empowerment are related to physical violence but the relationship is context specific. There may be a host of other factors that are related to physical violence but we limited our investigation to child marriage and women empowerment with other possible covariates. This study reiterates that physical violence is deeply entrenched in both culturally distinct states with a varied proportion. However, the pattern and correlates of physical violence are different in these two states which may be due to distinct culture and stages of socioeconomic progress in Tamil Nadu and Bihar.

Curbing violence needs a culture specific intervention. Addressing an issue such as violence that has remained a private domain and has been secretly dealt with in India needs involvement of men and women alike. Family as a primary unit need to be targeted to educate them on the ill effects of violence in the life of a woman and her offspring. The structures of the family in these two states are very different. An in-depth qualitative study exploring the cultural influence on violence against women may provide a road map for the intervention.

Combating violence and eradicating child marriage are very necessary to ensure human rights protection for the women. Provision for better education may help delay the age at marriage and empower women. At the same time, the government needs to urgently establish crisis center to provide treatment and recognize violence against women as a public health problem as it has negative consequences on women's health and wellbeing [5,7-9]. The future generations pulled out of school early with no skills to access employment opportunity become part of the vicious cycle of poverty. Child marriage is a problem not only to the bride but to her children, society, and nation as a whole.

\section{Conflict of Interests}

The authors declare that there is no conflict of interests regarding the publication of this paper.

\section{References}

[1] UNICEF, Ending Child Marriage: Progress and Prospects, UNICEF, New York, NY, USA, 2014, http://www.unicef.org/ media/files/Child_Marriage_Report_7_17_LR..pdf.

[2] Ministry of Health and Family Welfare, National Population Policy 2000, Government of India, New Delhi, India, 2000.

[3] Ministry of Youth Affairs and Sports, National Youth Policy 2003, Government of India, New Delhi, India, 2003.

[4] Ministry of Law and Justice, Prohibition of Child Marriage Act (2006), No. 6 of 2007, Jan. 10, Government of India, 2007.

[5] ICRW, Too Young to Wed: The Lives, Rights and Health of Young Married Girls, ICRW, Washington, DC, USA, 2003, http://www.icrw.org/files/publications/Too-Young-to-Wed-theLives-Rights-and-Health-of-Young-Married-Girls.pdf.

[6] UNICEF, Child Marriage in India: An Analysis of Available Data, UNICEF, New Delhi, India, 2012, http://www.unicef.in/Itstartswithme/childmarriage.pdf.

[7] J. G. Silverman, M. R. Decker, N. Saggurti, D. Balaiah, and A. Raj, "Intimate partner violence and HIV infection among married Indian women," Journal of the American Medical Association, vol. 300, no. 6, pp. 703-710, 2008.

[8] N. N. Sarkar, "The impact of intimate partner violence on women's reproductive health and pregnancy outcome," Journal of Obstetrics and Gynaecology, vol. 28, no. 3, pp. 266-271, 2008.

[9] L. K. Ackerson and S. V. Subramanian, "Domestic violence and chronic malnutrition among women and children in India," American Journal of Epidemiology, vol. 167, no. 10, pp. 1188-1196, 2008.

[10] A. Raj, N. Saggurti, D. Lawrence, D. Balaiah, and J. G. Silverman, "Association between adolescent marriage and marital violence among young adult women in India," International Journal of Gynecology and Obstetrics, vol. 110, no. 1, pp. 35-39, 2010.

[11] International Institute for Population Sciences (IIPS) and Macro International, National Family Health Survey (NFHS-3), 2005-6, vol. 1, Mumbai, India, 2007.

[12] S. Kishor and K. Johnson, Profiling Domestic Violence: A Multi-Country Study, ORC Macro, MEASURE DHS, Calverton, Md, USA, 2004, http://www.measuredhs.com/pubs/pdf/OD31/ OD31.pdf.

[13] A. Raj, N. Saggurti, D. Balaiah, and J. G. Silverman, "Prevalence of child marriage and its effect on fertility and fertility-control outcomes of young women in India: a cross-sectional, observational study," The Lancet, vol. 373, no. 9678, pp. 1883-1889, 2009.

[14] S. J. Jejeebhoy, "Wife-beating in rural India: husband's right? Evidence from survey data," Economic and Political Weekly, vol. 33, pp. 855-862, 1998.

[15] K. G. Santhya and S. J. Jejeebhoy, "Early marriage and HIV/AIDS risk factors among young women in India," Economic and Political Weekly, vol. 42, no. 14, pp. 1291-1297, 2007.

[16] I. S. Speizer and E. Pearson, "Association between early marriage and intimate partner violence in India: a focus on youth from Bihar and Rajasthan," Journal of Interpersonal Violence, vol. 26, no. 10, pp. 1963-1981, 2011.

[17] L. Heise, M. Ellsberg, and M. Gottmoeller, "A global overview of gender-based violence," International Journal of Gynecology and Obstetrics, vol. 78, no. 1, pp. S5-S14, 2002.

[18] S. Sabarwal, K. G. Santhya, and S. J. Jejeebhoy, "Women's autonomy and experience of physical violence within marriage in rural India: evidence from a prospective study," Journal of Interpersonal Violence, vol. 29, no. 2, pp. 332-347, 2014. 
[19] L. Visaria, "Violence against women in India," Economic and Political Weekly, vol. 43, pp. 60-66, 2008.

[20] T. Dyson and M. Moore, "On kinship structure, female autonomy, and demographic behavior in India," Population \& Development Review, vol. 9, no. 1, pp. 35-60, 1983.

[21] I. Karve, Kinship Organization in India, vol. 11 of Deccan College Monograph Series, G.S.Press, Madras, India, 1953.

[22] Census of India, Provisional population totals, paper 1 (Census document), 2011, http://www.censusindia.gov.in/2011-provresults/prov_results_paperl_india.html.

[23] ORGI, “Sample Registration System 49(1)," 2014, http://censusindia.gov.in/vital_statistics/SRS_Bulletins/SRS\%20Bulletin\%20Sepetember\%202014.pdf.

[24] ORGI, "SRS Special Bulletin on Maternal Mortality in India 2010-12," 2013, http://www.censusindia.gov.in/vital_statistics/ SRS_Bulletins/MMR_Bulletin-2010-12.pdf.

[25] M. A. Straus, S. L. Hamby, S. Boney-McCoy, and D. B. Sugarman, "The revised conflict tactics scales (CTS2): development and preliminary psychometric data," Journal of Family Issues, vol. 17, no. 3, pp. 283-316, 1996.

[26] L. R. Tucker and C. Lewis, "A reliability coefficient for maximum likelihood factor analysis," Psychometrika, vol. 38, no. 1, pp. 1-10, 1973.

[27] M. A. Koenig, R. Stephenson, S. Ahmed, S. J. Jejeebhoy, and J. Campbell, "Individual and contextual determinants of domestic violence in North India," American Journal of Public Health, vol. 96, no. 1, pp. 132-138, 2006.

[28] K. G. Santhya, N. Haberland, F. Ram, R. K. Sinha, and S. K. Mohanty, "Consent and coercion: examining unwanted sex among married young women in India," International Family Planning Perspectives, vol. 33, no. 3, pp. 124-132, 2007.

[29] C. H. Rocca, S. Rathod, T. Falle, R. P. Pande, and S. Krishnan, "Challenging assumptions about women's empowerment: social and economic resources and domestic violence among young married women in urban South India," International Journal of Epidemiology, vol. 38, no. 2, pp. 577-585, 2009. 

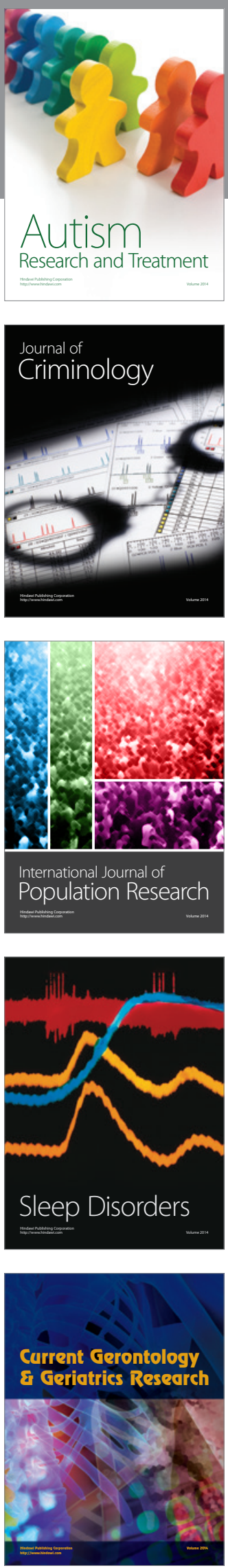
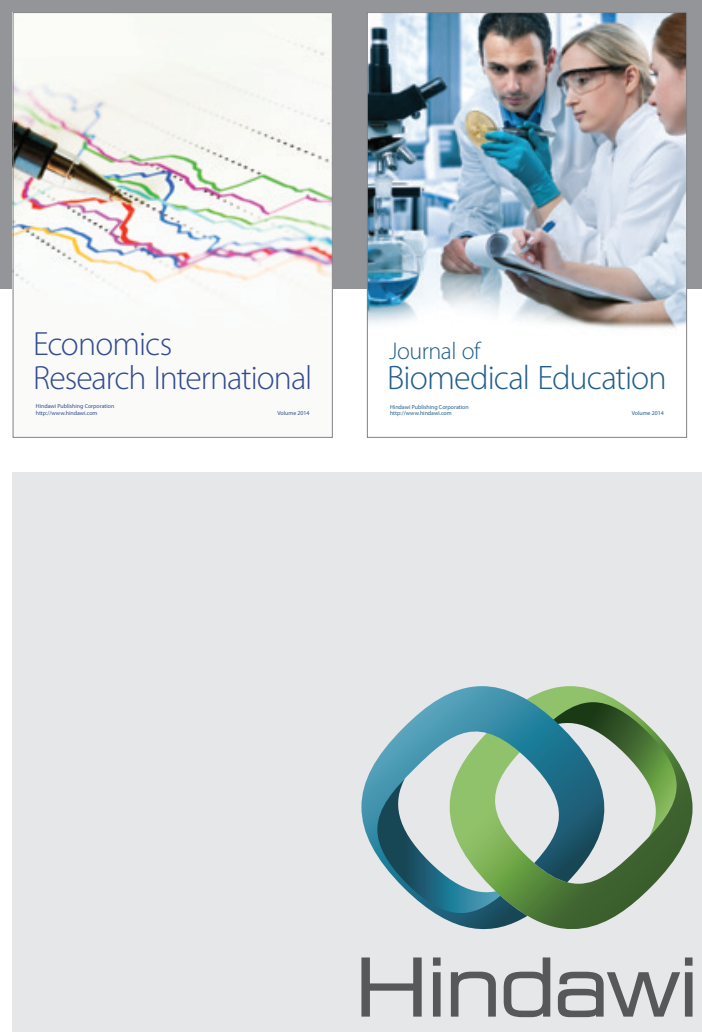

Submit your manuscripts at

http://www.hindawi.com
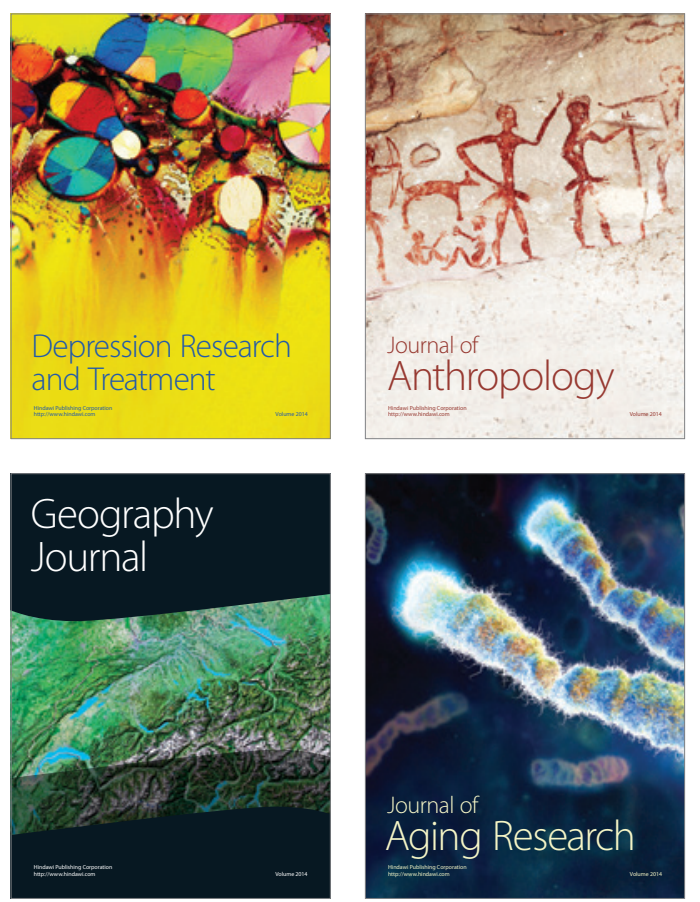
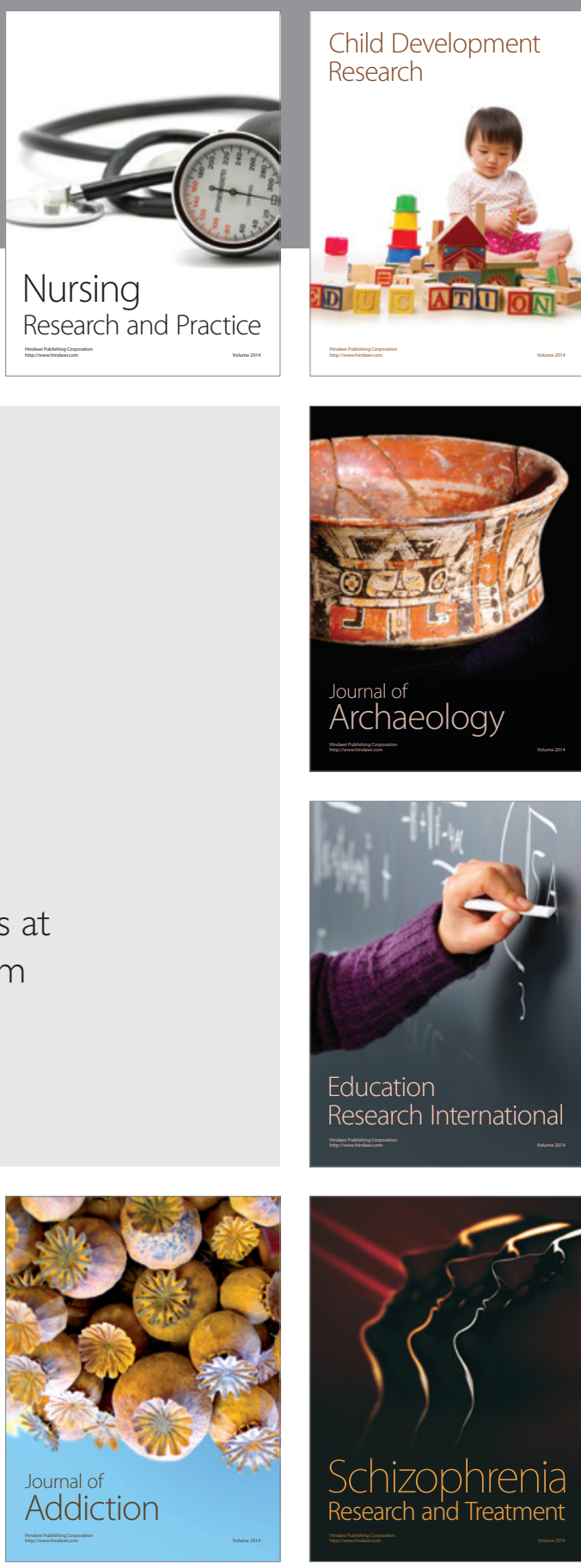

(D)
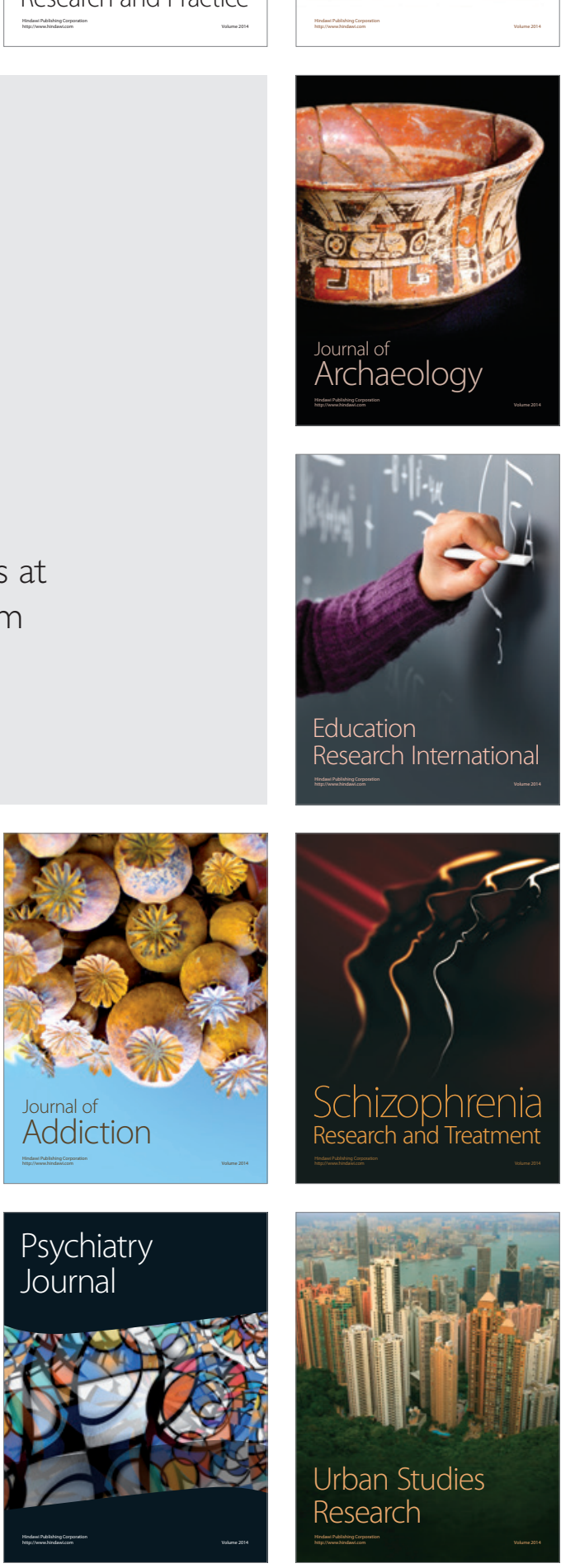